\title{
Intermittent episodes of metabolic ketoacidosis in a seven-year-old boy: Mitochondrial Beta-ketothiolase deficiency
}

\author{
Weerasinghe WAG, Jasinge E, Sarathchandra JC, Chinthaka RAK \\ Lady Ridgeway Hospital for Children, Colombo, Sri Lanka
}

Correspondence: Dr.W.A.G. Weerasinghe (wagweerasinghe@gmail.com)

\section{Introduction}

(Keywords: Beta-ketothiolase deficiency, tandem mass spectrometry)

Mitochondrial beta-ketothiolase deficiency (BKT) is a rare inborn error of metabolism. It was first reported in 1971 (1). Over 40 cases have been dealt with publications and more than 20 other cases have been reported worldwide (1). We report a child with BKT who was diagnosed recently at Lady Ridgeway Hospital for children. This is the first reported case in Sri Lanka.

\section{Case Report}

A seven-year-old boy, the first born to second degree consanguineous parents, presented with a three days history of vomiting and low grade fever followed by drowsiness. Clinically child was afebrile, well hydrated, drowsy yet conscious with no focal neurological signs. Acidotic breathing was present. High anion gap metabolic acidosis was evident with initial investigations (Table 1). Urine ketone bodies were positive, but reducing substances were not detected. Analysis of cerebrospinal fluid was normal. Child recovered gradually with bicarbonate therapy and hydration with intravenous fluids. A similar episode has occurred at four years of age, managed at intensive care unit with ventilator support.

With the two episodes of intermittent metabolic acidosis the child was screened for metabolic disorders by tandem mass spectrometry (MS/MS) in India. Dried blood spot on a Guthrie card was analyzed for acylcarnitine to screen fatty acid oxidation disorders and organic acid disorders. 3-hydroxyisovaleryl carnitine $(\mathrm{C} 5 \mathrm{OH})$ concentration was above normal and this elevation was attributed to the following inborn errors: 3-methyl
crotonyl-CoA-carboxylase (3-MCC) deficiency, 3-methylglutrayl-CoA (HMG) lyase deficiency, 3-methylglutaconyl-CoA (3-MGA) hydratase deficiency and beta-ketothiolase deficiency (BKT).

Table 1: Serum and plasma laboratory investigations

\begin{tabular}{|c|c|c|}
\hline Analyte & Result & Reference Range \\
\hline Sodium & 138 & $135-145 \mathrm{mmol} / \mathrm{L}$ \\
\hline Potassium & 4.4 & $3.5-5.3 \mathrm{mmol} / \mathrm{L}$ \\
\hline Chloride & 108 & $98-107 \mathrm{mmol} / \mathrm{L}$ \\
\hline Corrected $\mathrm{Ca}^{+2}$ & 2.65 & $2.2-2.7 \mathrm{mmol} / \mathrm{L}$ \\
\hline Blood urea & 3.8 & $1.8-6.4 \mathrm{mmol} / \mathrm{L}$ \\
\hline Serum Creatinine & 33 & $27-62 \mu \mathrm{mol} / \mathrm{L}$ \\
\hline Glucose & 7 & $3.8-7.7 \mathrm{mmol} / \mathrm{L}$ \\
\hline ALT & 20 & $10-40 \mathrm{IU} / \mathrm{L}$ \\
\hline AST & 48 & $9-48 \mathrm{IU} / \mathrm{L}$ \\
\hline $\mathrm{pH}$ & 7.1 & $7.35-7.45$ \\
\hline $\mathrm{PO}_{2}$ & 105 & $83-108 \mathrm{mmHg}$ \\
\hline $\mathrm{PCO}_{2}$ & 15 & $35-45 \mathrm{mmHg}$ \\
\hline Bicarbonate & 5.8 & $24-26 \mathrm{mmol} / \mathrm{L}$ \\
\hline Base excess & -22 & -2 to +2 \\
\hline Anion gap & 24.2 & $10-14 \mathrm{mmol} / \mathrm{L}$ \\
\hline Lactic acid & 1.4 & $1-1.8 \mathrm{mmol} / \mathrm{L}$ \\
\hline Ammonia & 40 & $20-50 \mu \mathrm{mol} / \mathrm{L}$ \\
\hline $\mathrm{Hb}$ & 12 & $11.1-14.1 \mathrm{~g} / \mathrm{dl}$ \\
\hline WBC & $6.5 \times 10$ & \\
\hline Platelets & $250 \times 10$ & \\
\hline PCV & $0.36 \%$ & $0.3 \%-0.38 \%$ \\
\hline
\end{tabular}


Later on after complete recovery of the acute stage, an organic acid analysis of urine was performed by gas chromatography mass spectrometry (GC/MS) in India. It revealed a markedly elevated urinary excretion of tiglylglycine and slightly elevated 2-methyl-3-OH-butyric acid, which is observed in either beta-ketothiolase deficiency or in 2-methyl-3hydroxybutyryl-CoA dehydrogenase deficiency. With clinical correlation BKT deficiency was diagnosed. The child was advised to have a mild protein restricted diet, especially isoleucine containing foods, and avoidance of fasting states. Currently, the child is apparently well.

\section{Discussion}

Beta-ketothiolase deficiency is a defect of mitochondrial acetoacetyl-CoA thiolase enzyme involve in the pathway of ketone body metabolism and isoleucine catabolism. Its inheritance is autosomal recessive with ACAT1 gene involvement (2).
It is characterized by normal early development followed by progressive loss of mental and motor skills; it is clinically characterized by acute episodic ketoacidosis (3).

These episodes usually occur after inter current illnesses and respond quickly to intravenous fluids and bicarbonate therapy. If the disease is diagnosed early and treated by fasting avoidance and modest protein restriction, ketoacidosis episodes can be prevented and the prognosis is excellent.

In contrast, 2-methyl-3-hydroxybutyryl-CoA dehydrogenase (MHBD) deficiency is relatively a rare defect which present with predominantly neurological manifestations, although acute metabolic decompensation may occur in the early newborn period ${ }^{3}$. Therefore, careful examination of urine organic acids is required for identification and differential diagnosis of these disorders, with awareness that the abnormalities may be subtle and variable (3). In laboratory diagnosis of BKT, the elevated urinary metabolite most characteristic is 2-methyl-3-hydroxybutyric acid (Figure 1).

\section{ENZYME}

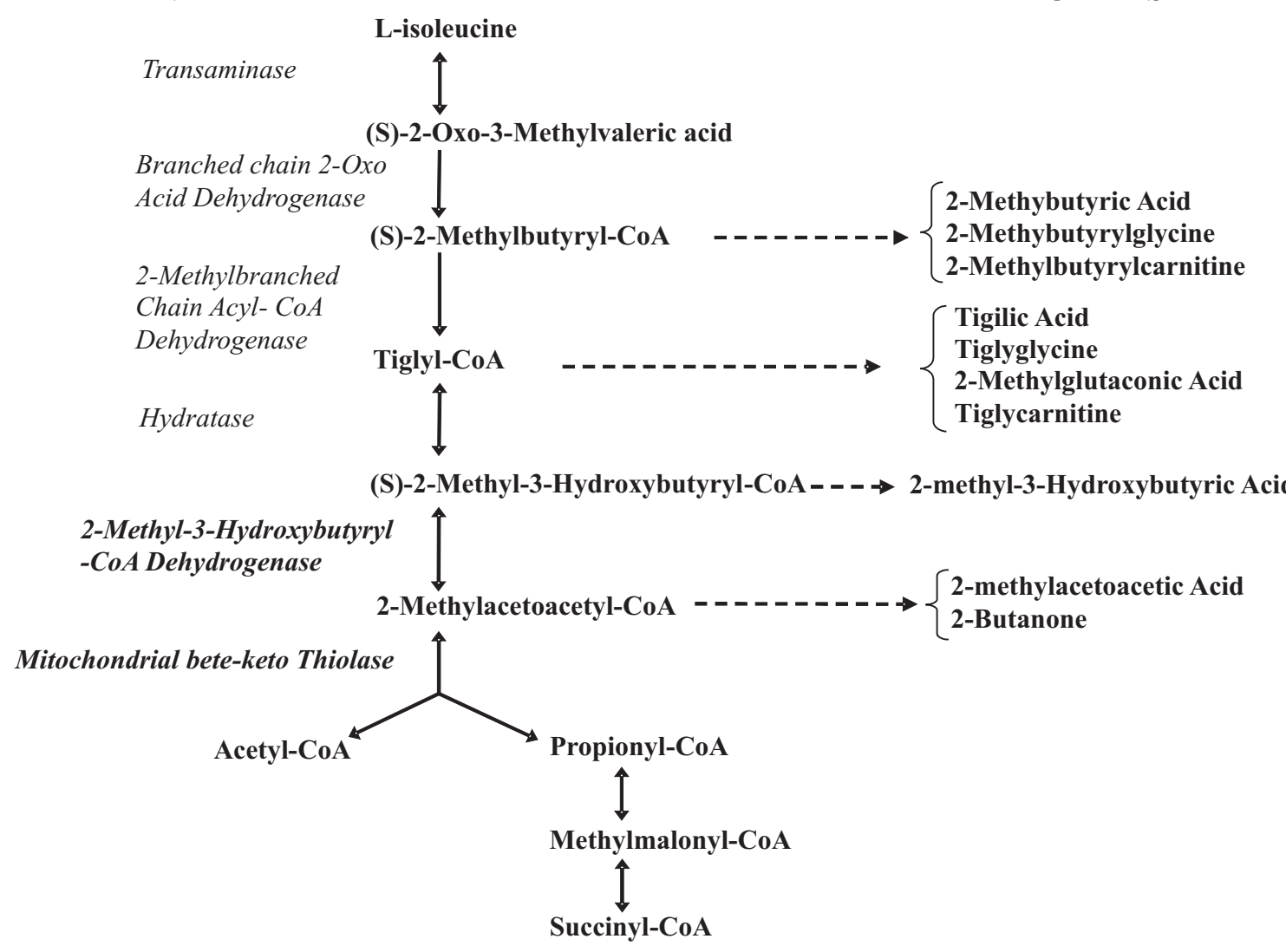

Figure 1: Catabolism of isoleucine pathway. The structures and the names of intermediates of the pathway of catabolism of isoleucine are shown in the center, with the names of the enzymes on the left and the metabolites that may be elevated due to a deficiency of these enzymes shown on the right. 
This is often accompanied by elevation of 2-methylacetoacetic acid and its decarboxylation product 2-butanone. However, 2-methyl acetoacetic acid is usually not detected by GC / MS because, it is inherently labile and it rapidly decarboxylates to 2-butanone (4). Moreover, both 2-methyl acetoacetic acid and 2-butanone are highly volatile and always not detected, unless fresh samples are studied $(4,5)$. Concurrently, in some known cases of BKT deficiency, there is very low excretion of 2-methyl acetoacetate or even nil at time especially in remission (5). Therefore, the absence of 2-methyl acetoacetate does not rule out BKT.

At the same time, 2-methylacetoacetic acid is not the most elevated metabolite seen in BKT, though it is the immediate substrate for the defective enzyme and might be expected to be most elevated (2). Rather, due to reversible reaction of 3-hydroxyacyl-CoA dehydrogenase and the normal high ratio of NADH to NAD, the reduced compound 2-methyl-3hydroxybutyric acid is more elevated (2). In this case 2-methyl-3- hydroxyl-butyric acid was slightly elevated giving a clue towards the diagnosis. Most patients with BKT also excrete significantly elevated amounts of tiglylglycine (2), as similarly occurred in this case. But in some cases of BKT this metabolite does not rise. In fact, the pattern and amount of excretion of all metabolites is variable (2).

With the above biochemical evidence and clinical correlation the most possible diagnosis was betaketothiolase deficiency. However, analysis of enzyme activity is preferred for confirmation of diagnosis if that was feasible.

\section{Acknowledgements}

Dr. Rohit Cariappa, chief scientist and vice president of NeoGen lab, India for free of charge MS/MS screening.

\section{References}

1. Fukao T, Charles R, Kondo N, et al. The clinical phenotype and outcome of mitochondrial acetoacetyl-CoA thiolase deficiency in 26 enzymatically proved and mutationdefined patients. Molecular genetics and metabolism 2001; 72: 109-14.

2. Lawrence S, Julian CW. Branched chain organic aciduria. In: Scriver, Beaudet, Valle, Sly eds. The Metabolic and molecular bases of inherited disease. Volume 2 ( $8^{\text {th }}$ edition) 2001:2144-6.

3. Stanley H. Korman. Inborn errors of isoleucine degradation: A review. Molecular Genetics and Metabolism 2006; 89: 289-99.

4. P.T. Ozand et al, 3-ketothiolase deficiency: a review and four patients with neurologic symptoms. Brain and Development 1994; 16(Suppl); 38-45.

5. Fukao T. Beta-ketothiolase deficiency, Orphanet encyclopedia, September 2004. Http:/www.orpha.net/ data/patho/GB/uk-T2.pdf 